2 Merikangas KR, Fenton BT, Cheng SH, Stolar MJ, Risch N. Association between migraine and stroke in a large-scale epidemiological study of the United States. Arch Neurol 1997;54:362-8.

3 Henrich JB, Horwitz RI. A controlled study of ischaemic stroke risk in migraine patients. J Clin Epidemiol 1989;42:773-80.

4 Tzourio C, Tehindrazanarivelo A, Iglésias S, Alperovich A, Chedru F, d'Anglejan-Chatillon J, et al. Case-control study of migraine and risk of ischaemic stroke in young women. BMJ 1995;310:830-3.

5 Carolei A, Marini C, De Matteis G. History of migraine and risk of cerebral ischaemia in young adults. Lancet 1996;347:1503-6

6 Marini C, Carolei A, Roberts RS, Prencipe M, Gandolfo C, Inzitari D et al, and the National Research Council Study Group. Focal cerebral ischaemia in young adults: a collaborative case-control study. Neuroepidemiology 1993;12:70-1.

7 Welch KMA, Levine SR. Migraine-related stroke in the context of the International Headache Society classification of head pain. Arch Neurol 1900;47:458-62.

8 Bogousslavsky J, Regli F, Van Melle G, Payot M, Uske A. Migraine stroke. Neurology 1988;38:223-7.

9 Rothrock JF, Walicke P, Swenson MR, Lyden PD, Logan WR. Migrainous stroke. Arch Neurol 1988;45:63-7.

10 Bickerstaff ER. Neurological complications of oral contraceptives. Oxford: Oxford University Press, 1975

11 Migraine and oral contraception. Drug Ther Bull 1987;25:95-6.

12 Petitti DB, Sidney S, Bernstein A, Wolf S, Quesenberry C, Ziel HK, et al. Stroke in users of low-dose oral contraceptives. New Engl J Med 1996;335:8-15.

13 World Health Organization Collaborative Study of Cardiovascular Disease and Steroid Hormone Contraception. Ischaemic stroke and combined oral contraceptives: results of an international multicentre, case-control study. Lancet 1996;348:498-510.
14 World Health Organization Collaborative Study of Cardiovascular Disease and Steroid Hormone Contraception. Haemorrhagic stroke, overall stroke risk, and combined oral contraceptives: results of an international, multicentre, case-control study. Lancet 1996;348:505-10.

15 World Health Organization Collaborative Study of Cardiovascular Disease and Steroid Hormone Contraception. A multinational study of cardiovascular disease and steroid hormone contraceptives: description and validation of methods. J Clin Epidemiol 1995;48:1513-47.

16 Classification and diagnostic criteria for headache disorders, cranial neuralgias and facial pain. Headache Classification Committee of the International Headache Society. Cephalagia 1988;8(suppl 7):1-96.

17 Maldonado G, Greenland S. Simulation study of confounder-selection strategies. Am J Epidemiol 1993;138:923-36.

18 Darney PD. The androgenicity of progestins. Am J Med 1995;98:104-10S.

19 Collaborative Group for the Study of Stroke in Young Women. Oral contraceptives and stroke in young women: associated risk factors. JAMA 1975;231:718-22.

20 Buring JE, Hebert R, Romero J, Kittross A, Cook N, Manson J, et al. Migraine and subsequent risk of stroke in the Physicians' Health Study. Arch Neurol 1995;52:129-34.

21 World Health Organization Collaborative Study of Cardiovascular Disease and Steroid Hormone Contraception. Venous thromboembolic disease and combined oral contraceptives: results of international multicentre case-control study. Lancet 1995;346:1575-82.

22 The World Health Organization Collaborative Study of Cardiovascular Disease and Steroid Hormone Contraception. Acute myocardial infarction and combined oral contraceptives: results of an international multicentre case-control study. Lancet 1997;349:1202-9.

23 Welch KMA. Relationship of stroke and migraine. Neurology 1994;44(suppl 7):533-6.

(Accepted 23 October 1998)

\title{
Social class in childhood and general health in adulthood: questionnaire study of contribution of psychological attributes
}

Hans Bosma, H Dike van de Mheen, Johan P Mackenbach

Erasmus University Rotterdam, Department of Public Health, PO Box $1738,3000 \mathrm{DR}$ Rotterdam,

Netherlands

Hans Bosma, senior researcher H Dike van de Mheen,

senior researcher

Johan P

Mackenbach,

professor

Correspondence to: Dr Bosma bosma@ mgz.fgg.eur.nl

BMJ 1999;318:18-22

\section{Abstract}

Objective To determine the contribution of psychological attributes (personality characteristics and coping styles) to the association between social class in childhood and adult health among men and women.

Design Partly retrospective, partly cross sectional study conducted in the framework of the Dutch GLOBE study.

Subjects Sample of general population from south east Netherlands consisting of 2174 men and women aged 25-74 years. Baseline self reported data from 1991 provided information on childhood and adult social class, psychological attributes, and general health.

Main outcome measure Self rated poor health. Results Independent of adult social class, low childhood social class was related to self rated poor health (odds ratio 1.67 (95\% confidence interval 1.02 to 2.75 ) for subjects whose fathers were unskilled manual workers versus subjects whose fathers were higher grade professionals). Subjects whose fathers were manual workers generally had more unfavourable personality profiles and more negative coping styles. External locus of control, neuroticism, and the absence of active problem focused coping explained about half of the association between childhood social class and self rated poor health. The findings were independent of adult social class and height.
Conclusions A higher prevalence of negative personality profiles and adverse coping styles in subjects who grew up in lower social classes explains part of the association between social class in childhood and adult health. This finding underlines the importance of psychological mechanisms in the examination of the negative effects of adverse socioeconomic conditions in childhood.

\section{Introduction}

There is now increasing evidence that differences in adult health are partly caused by socioeconomic factors during early life and upbringing. ${ }^{1-5}$ The causal mechanisms relating adverse socioeconomic conditions in childhood and poor health in adulthood have not yet been examined extensively. Biological mechanisms, such as hypertension and hypercholesterolaemia, have been suggested, ${ }^{6-8}$ and there is some evidence for mechanisms related to lifestyle, such as smoking and physical activity. ${ }^{3-12}$ With few exceptions the contribution of psychological attributes, such as personality factors and coping styles, has hardly been examined. ${ }^{10}{ }^{13} 14$ Psychological attributes are partially rooted in environmental conditions in childhood, (learning) experiences, and rearing styles. ${ }^{14-16}$ There is now also increasing evidence that psychological attributes influence health through behavioural mechanisms (for example, smoking) or direct physiological mechanisms, or both. ${ }^{17}$ Unhealthy personality factors and coping strategies may, therefore, be 
mechanisms through which adverse socioeconomic conditions in childhood contribute to poor health in adulthood. Baseline data from the Dutch GLOBE study (a Dutch study on health and living conditions of the population of Eindhoven and its surroundings) allowed us to examine whether childhood social class is related to psychological attributes and whether psychological attributes are mediating factors in the association between social class in childhood and adult health. To obtain the direct effects, we accounted for adult social class separately. ${ }^{18}$

\section{Subjects and methods}

\section{Study population}

Data were collected within the framework of the GLOBE study. A postal survey was conducted in 1991 among 27070 non-institutionalised inhabitants (aged 15-74 years) of Eindhoven and a number of surrounding municipalities, all in the south eastern part of the Netherlands. Stratified by age and post code, the sample was randomly drawn from the municipal population registries. People aged $45-70$ years old and people from the highest and lowest social classes were overrepresented to allow specific analyses for middle aged subjects and to increase socioeconomic contrasts. The response rate was $70.1 \%$, which resulted in a study population of 18973 . The response rates were not substantially different for age, sex, marital status, level of urbanisation, or social class. ${ }^{19} \mathrm{~A}$ few months later a subsample of those who responded to the postal questionnaire was approached for a more extensive oral interview. This subsample consisted of 3529 randomly chosen respondents to the postal questionnaire, of whom 2802 agreed to be interviewed (79.4\%). The response rates hardly differed for relevant demographic characteristics. More details on the study design can be found elsewhere. ${ }^{19}$ To allow for a more valid measurement of adult social class the analyses were restricted to men and women older than 24 years $(n=2462)$. The analyses were based on subjects who reported both their father's and their own adult occupational level $(n=2174)$.

\section{Social class, psychological attributes, and health outcome}

Adult social class was measured by the respondent's current or last occupational level. Childhood social class was measured retrospectively by the father's occupational level when the respondent was 12 years old. If the father was not in paid employment the father's last occupation in paid employment was used. The occupations of both the respondent and the father were classified according to the scheme of Erikson, Goldthorpe, and Portocarero. ${ }^{20}$ The psychological attributes were assessed by questionnaires on personality characteristics and coping styles. The personality characteristics were external locus of control (low perceived control), ${ }^{21}{ }^{22}$ neuroticism (emotional distress), ${ }^{2 .}$ parochialism (a narrow, local, and non-scientific attitude), ${ }^{24-26}$ and orientation towards the future. ${ }^{25}{ }^{26}$ Seven typical styles of coping were distinguished: active problem focusing, avoidance behaviour, depressive reaction pattern, social support seeking, palliative reaction pattern, disclosure of emotions, and optimism. ${ }^{27}$
The items were summed for the separate scales and then divided into thirds.

A perception of "less than good" general health was used as a general measure of health $(n=621 ; 29 \%)$. This was based on the subject's answer to the question: "How do you rate your health in general?" (very good; good; fair; sometimes good and sometimes poor; poor). Perceived general health has been shown to be strongly related to physical health and to survival. ${ }^{28}{ }^{29} \mathrm{~A}$ "less than good" perceived general health is hereafter referred to as poor general health.

\section{Statistical analysis}

Childhood social class and the psychological attributes were related by logistic regression analysis with adjustment for age and sex. For this analysis the psychological attributes were divided into two categories by combining the lowest two thirds. This analysis provided adjusted estimated percentages. Childhood social class and adult health were also related by logistic regression analysis controlled for age, sex, marital status (married, single, widowed/divorced), religious affiliation (none, Catholic, Protestant/other), and level of urbanisation (four levels). To examine the contribution of psychological attributes to the association of childhood social class and adult health, the psychological attributes (in thirds) were separately introduced into a model with childhood social class and confounders. As we were primarily interested in the direct effects of childhood social class on adult health, all analyses were separately adjusted for adult social class. Self reported height as a proxy for factors in early life was also separately controlled for. As the findings for men and women were similar, we combined data for both and controlled for sex.

\section{Results}

Table 1 shows that childhood social class was related to personality. External locus of control (42\% v 15\%), parochialism $(35 \%$ v 12\%), neuroticism $(34 \%$ v $23 \%)$, and lack of future orientation $(41 \% v 27 \%)$ were more prevalent in the lowest compared with the highest social classes in childhood. The prevalence decreased almost linearly from lowest to highest class but was somewhat less clear for neuroticism. Low childhood social class was also related to particular coping styles-that is, a lower prevalence of active problem focused coping $(20 \%$ v 40\%), a somewhat more frequent depressive reaction pattern $(26 \%$ v $18 \%)$, avoidance $(28 \%$ v 22\%), less often seeking social support $(21 \%$ v 36\%), and less often expressing emotions (26\% v 35\%). Except for active problem focused coping, these associations were not linear. When we controlled for adult social class the associations were weaker, but most remained.

Table 2 shows that childhood social class was related to poor general health. Subjects with a low childhood social class were 2.1 times as likely to rate their health as poor than subjects with a high childhood social class. Adjustment of this odds ratio for adult social class decreased the odds ratio to 1.67 , which was still significant.

Two personality factors and one coping style contributed to the association between childhood social class and adult health: external locus of control, 
Table 1 Numbers (percentages) of subjects with psychological attributes adjusted for age and sex by social class in childhood $\dagger$

\begin{tabular}{|c|c|c|c|c|c|c|c|c|c|c|c|c|}
\hline \multirow[b]{2}{*}{ Detail } & \multirow[b]{2}{*}{$\begin{array}{c}\text { No of } \\
\text { subjects }\end{array}$} & \multicolumn{4}{|c|}{ Personality factors* } & \multicolumn{7}{|c|}{ Coping styles } \\
\hline & & $\begin{array}{l}\text { External } \\
\text { locus of } \\
\text { control }\end{array}$ & Parochialism & Neuroticism & $\begin{array}{l}\text { Lack of } \\
\text { future } \\
\text { orientation }\end{array}$ & $\begin{array}{c}\text { Active } \\
\text { problem } \\
\text { focusing }\end{array}$ & $\begin{array}{l}\text { Depressive } \\
\text { reaction }\end{array}$ & Avoidance & $\begin{array}{l}\text { Social } \\
\text { support } \\
\text { seeking }\end{array}$ & $\begin{array}{c}\text { Palliative } \\
\text { reaction }\end{array}$ & $\begin{array}{l}\text { Expression } \\
\text { of emotions }\end{array}$ & Optimism \\
\hline \multicolumn{13}{|c|}{ Childhood social class: } \\
\hline 1 (high) & 137 & $21(15)$ & $16(12)$ & $32(23)$ & $37(27)$ & $55(40)$ & $25(18)$ & $30(22)$ & $49(36)$ & $37(27)$ & $48(35)$ & $36(26)$ \\
\hline 2 & 447 & $98(22)$ & 67 (15) & $134(30)$ & $152(34)$ & $125(28)$ & $125(28)$ & $85(19)$ & $134(30)$ & $107(24)$ & $125(28)$ & $103(23)$ \\
\hline 3 & 456 & $128(28)$ & $146(32)$ & $114(25)$ & $151(33)$ & $119(26)$ & $105(23)$ & $105(23)$ & $100(22)$ & $96(21)$ & $96(21)$ & $109(24)$ \\
\hline 4 & 649 & $221(34)$ & $182(28)$ & $175(27)$ & $240(37)$ & $149(23)$ & $136(21)$ & $143(22)$ & $149(23)$ & $143(22)$ & $162(25)$ & $169(26)$ \\
\hline 5 (low) & 485 & $204(42)$ & $170(35)$ & $165(34)$ & $199(41)$ & $97(20)$ & $126(26)$ & $136(28)$ & $102(21)$ & $112(23)$ & $126(26)$ & $107(22)$ \\
\hline
\end{tabular}

Model 2 (adjusted for adult social class)§

Childhood social class:

\begin{tabular}{lrrrrrrrrrrrr}
\hline 1 (high) & 137 & $23(17)$ & $30(22)$ & $36(26)$ & $29(21)$ & $53(39)$ & $22(16)$ & $40(29)$ & $51(37)$ & $30(22)$ & $45(33)$ & $45(33)$ \\
\hline 2 & 447 & $107(24)$ & $103(23)$ & $152(34)$ & $121(27)$ & $130(29)$ & $112(25)$ & $112(25)$ & $139(31)$ & $89(20)$ & $121(27)$ & $130(29)$ \\
\hline 3 & 456 & $114(25)$ & $192(42)$ & $119(26)$ & $109(24)$ & $132(29)$ & $91(20)$ & $123(27)$ & $109(24)$ & $78(17)$ & $91(20)$ & $132(29)$ \\
\hline 4 & 649 & $182(28)$ & $227(35)$ & $182(28)$ & $169(26)$ & $175(27)$ & $117(18)$ & $169(26)$ & $169(26)$ & $117(18)$ & $162(25)$ & $201(31)$ \\
\hline 5 (low) & 485 & $165(34)$ & $194(40)$ & $170(35)$ & $136(28)$ & $121(25)$ & $107(22)$ & $155(32)$ & $116(24)$ & $87(18)$ & $126(26)$ & $126(26)$ \\
\hline
\end{tabular}

*Proportion of subjects in highest third of distribution of psychological attributes.

†Childhood social class: (1) higher grade professionals, (2) lower grade professionals or routine non-manual workers, (3) self employed workers, (4) skilled manual workers, and (5) unskilled manual workers. Homemakers added as separate, sixth category for adult social class.

$\ddagger P \leqslant 0.05$ for all except palliative reaction and optimism (based on overall effect of childhood social class).

$\S \mathrm{P} \leqslant 0.05$ for all except lack of future orientation, avoidance, palliative reaction, and optimism (based on overall effect of childhood social class).

Table 2 Odds ratios* $(95 \%$ confidence intervals) for poor general health by social class in childhoodt; separately and simultaneously adjusted for external locus of control, neuroticism, and active problem focused coping

\begin{tabular}{|c|c|c|c|c|c|c|c|c|c|}
\hline \multirow[b]{3}{*}{ Detail } & \multirow[b]{3}{*}{$\begin{array}{l}\text { Model A: adjusted for } \\
\text { confounders only* }\end{array}$} & \multicolumn{8}{|c|}{ Model B: adjusted for confounders and following variable } \\
\hline & & \multicolumn{2}{|c|}{ External locus of control } & \multicolumn{2}{|c|}{ Neuroticism } & \multicolumn{2}{|c|}{ Active problem focused coping } & \multicolumn{2}{|c|}{ All three variables } \\
\hline & & $\begin{array}{l}\text { Odds ratio } \\
(95 \% \mathrm{Cl})\end{array}$ & $\begin{array}{c}\% \\
\text { Reductionf }\end{array}$ & $\begin{array}{l}\text { Odds ratio } \\
(95 \% \mathrm{Cl})\end{array}$ & $\begin{array}{c}\% \\
\text { Reductionf }\end{array}$ & $\begin{array}{l}\text { Odds ratio } \\
(95 \% \mathrm{Cl})\end{array}$ & $\begin{array}{c}\% \\
\text { Reduction } \neq\end{array}$ & $\begin{array}{l}\text { Odds ratio } \\
(95 \% \mathrm{Cl})\end{array}$ & $\begin{array}{c}\% \\
\text { Reductionf }\end{array}$ \\
\hline \multicolumn{10}{|c|}{ Childhood social class: } \\
\hline 1 (high) & 1.00 & 1.00 & & 1.00 & & 1.00 & & 1.00 & \\
\hline 2 & 1.39 (0.85 to 2.28$)$ & 1.28 (0.77 to 2.14$)$ & 0.28 & $1.20(0.72$ to 2.01$)$ & 0.49 & $1.35(0.81$ to 2.24$)$ & 0.10 & $1.18(0.69$ to 2.01$)$ & 0.54 \\
\hline 4 & 1.84 (1.15 to 2.96$)$ & 1.50 (0.92 to 2.45) & 0.41 & 1.68 (1.02 to 2.74$)$ & 0.19 & 1.67 (1.02 to 2.71$)$ & 0.20 & 1.49 (0.89 to 2.49$)$ & 0.42 \\
\hline 5 (low) & 2.10 (1.29 to 3.41$)$ & $1.60(0.97$ to 2.65$)$ & 0.46 & 1.75 (1.06 to 2.90$)$ & 0.32 & 1.90 (1.16 to 3.13$)$ & 0.18 & 1.49 (0.88 to 2.52$)$ & 0.56 \\
\hline \multicolumn{10}{|c|}{ Model 2 (adjusted for adult social class) } \\
\hline \multicolumn{10}{|c|}{ Childhood social class: } \\
\hline 1 (high) & 1.00 & 1.00 & & 1.00 & & 1.00 & & 1.00 & \\
\hline 2 & 1.36 (0.83 to 2.24$)$ & 1.29 (0.77 to 2.15$)$ & 0.19 & $1.19(0.71$ to 2.00$)$ & 0.47 & 1.35 (0.81 to 2.25$)$ & 0.30 & 1.18 (0.69 to 2.02$)$ & 0.50 \\
\hline 3 & $1.32(0.80$ to 2.18$)$ & $1.23(0.74$ to 2.05$)$ & 0.28 & $1.23(0.74$ to 2.06$)$ & 0.28 & $1.33(0.80$ to 2.21$)$ & 0 & $1.23(0.72$ to 2.10$)$ & 0.28 \\
\hline 4 & 1.50 (0.92 to 2.43$)$ & 1.36 (0.82 to 2.23$)$ & 0.28 & 1.39 (0.84 to 2.29$)$ & 0.22 & $1.43(0.87$ to 2.36$)$ & 0.14 & 1.37 (0.81 to 2.30$)$ & 0.26 \\
\hline
\end{tabular}

${ }^{*}$ Adjusted for age, sex, marital status, level of urbanisation, and religious affiliation.

†Childhood social class: (1) higher grade professionals, (2) lower grade professionals or routine non-manual workers, (3) self employed workers, (4) skilled manual workers, and (5) unskilled manual workers. Homemakers added as separate, sixth category for adult social class.

$\ddagger$ Only percentage reduction in odds ratios computed: $\left(\left(\mathrm{OR}_{\text {(model A) }}-0 \mathrm{R}_{\text {(model B) }}\right) /\left(0 \mathrm{R}_{\text {(model A) }}-1\right)\right) \times 100$.

neuroticism, and the absence of active problem focused coping. The other personality and coping factors individually explained less than $10 \%$ of the gradient (data not shown). External locus of control had the strongest contribution to the socioeconomic gradient in poor general health. When external locus of control was taken into account, the odds ratio for subjects whose fathers were unskilled manual workers decreased by $46 \%$ in the model without adult social class controlled for (odds ratio 1.60 in model 1) and by $33 \%$ in the model with adult social class controlled for (1.45 in model 2). This was closely followed by neuroticism (32\% and 34\%, respectively). Active problem focused coping explained a smaller part of the increased risk-namely, $18 \%$ and $8 \%$, respectively. When the three psychological attributes were considered simultaneously, about half of the association of low childhood social class with poor general health could be explained by a higher prevalence of external locus of control and neuroticism and a lower prevalence of active coping styles in subjects with a low childhood social class.

Height hardly affected any of our findings (data not shown). Less than $7 \%$ of the association between childhood social class and adult health was explained by height. Further adjustment for external locus of control, neuroticism, and active coping explained an additional $50 \%$ of the association. This is similar to the results of analyses without adjustment for height. Furthermore, we found no evidence for interactions between childhood and adult social class or between childhood or adult social class and personality or coping styles (data not shown).

\section{Discussion}

We have shown that particular personality factors and coping styles substantially contribute to the direct 
association between social class in childhood and adult health. Subjects whose fathers were unskilled manual workers generally had more unfavourable personality profiles and negative coping styles. External locus of control, neuroticism, and the absence of active problem focused coping explained half of the association between low social class in childhood and poor general health. The lack of influence of height may suggest a contributing role of psychological attributes and not just of fetal development and early growth. ${ }^{7}$ Given the finding that childhood social class may be particularly related to cardiovascular diseases, it is worth mentioning that we found similar results for reporting a severe heart condition or stroke (not shown). These findings, however, were not significant because of small numbers. Our findings suggest that psychological attributes are worth examining when the associations between social class in childhood and adult health are studied..$^{10} 13$

These findings indicate that personality is partially rooted in childhood social class. Rearing styles differ among social classes, resulting in long term effects on behaviour, emotion, and cognition. ${ }^{15}{ }^{16}$ Children from high class backgrounds may more easily experience and learn a sense of mastery and control because their parents have more resources (for example, money and knowledge). ${ }^{30-32}$ This may underlie our findings with locus of control and active problem focused coping. Similarly, neuroticism may also reflect or be the consequence of a perceived lack of control over outcomes and events. ${ }^{33}$ Neurotic people may more easily internalise emotions instead of taking problem oriented approaches. Our findings emphasise the importance of control related psychological factors for the development of socioeconomic inequalities in health. ${ }^{34}$ Further research should examine whether perceived control is related to physical health through its impact on health behaviours or physiological mechanisms, or both. Our findings also suggest that intervention programmes should take account of relevant psychological pathways-for example, through emphasising and increasing control beliefs in people from lower socioeconomic backgrounds-as advocated by the empowerment approach. ${ }^{35}$ Increasing control beliefs in those without real control may be futile, however, because intervention on control beliefs per se may do little to the structural determinants which generate these beliefs. ${ }^{10} 35$

\section{Methodological considerations}

A few methodological issues should be considered. Firstly, the design was cross sectional, whereas the ideal design would be to follow a cohort from birth into adulthood. This would allow a better examination of the causal pathways between childhood social class, psychological attributes, adult social class, and adult health. Our theoretical causal model was based on previous research that showed little effect of adult health on adult social class. ${ }^{36}$ Another assumption was that personality affects adult health and not vice versa. Although there is clear evidence of such a causal relation, ${ }^{17}$ reverse causation cannot be completely excluded.$^{38}$ Furthermore, we were primarily interested in the direct effects of childhood social class-that is, independent of adult social class. If specific personality traits affect occupational achievements, however, the
Key messages

- Regardless of adult social class, low social class in childhood is related to poor general health in adulthood

- Adverse personality profiles and negative coping styles are more common in people who grew up in lower social classes

- Psychological attributes, such as low perceived control, explain a substantial part of the direct association between childhood social class and adult health

- Psychological mechanisms may explain adverse health outcomes in adults who have a low socioeconomic background

contribution of personality and coping to any association will be underestimated when adult social class is adjusted for. On the other hand, adult socioeconomic conditions are likely to affect components of adult personality and coping styles. This suggests the importance of controlling for adult social class. Given this dilemma we presented findings both adjusted and unadjusted for adult social class.

Secondly, all measures were self reported, which may have resulted in overestimated associations because of negative affectivity. ${ }^{39}$ This tendency to complain may have particularly affected the self reported general health outcome, but it is less likely to have affected findings with the more "objective" health outcome- that is, self reported cardiovascular diseases (mentioned above; data not shown). The role of neuroticism is relevant here as it is sometimes used as a proxy measure for negative affectivity, and it contributed strongly to the association (both general health and cardiovascular health). Given the association with the more "objective" health outcome (cardiovascular diseases) we prefer to interpret neuroticism as reflecting worry about lack of control ${ }^{33}$ instead of negative affectivity. Worry about lack of control has recently been shown to be correlated with an increased risk of coronary heart disease. ${ }^{40}$ To exclude the possibility of reporting bias as much as possible, further research should use alternative, more objective information on the health outcomes.

Thirdly, self reported height was an imperfect measure of early life factors related to prenatal and postnatal growth, and related biological consequences, because it was self reported and because adult height reflects more than just early growth. ${ }^{41}$ Fourthly, the inclusion of other psychological mechanisms, such as feelings of parental caring, ${ }^{42}$ childhood conscientiousness, ${ }^{43}$ and attachment via hostility, ${ }^{44}$ may have had an additional contribution to the association between childhood social class and adult health. Finally, the 288 people for whom data on social class in childhood or adulthood were missing had lower educational levels and poor general health than those who responded to both questions (not shown). This partial non-response is likely to have resulted in underestimated associations between childhood social class and adult health. 


\section{Conclusions}

Adverse socioeconomic conditions in childhood are related to poor general health in adulthood. Unhealthy psychological attributes (personality factors and coping styles) are more common in people who reported low childhood social class. Specific psychological attributes contribute substantially to the association between childhood social class and adult health. Perceived control may be the underlying psychological characteristic. When the influence of childhood socioeconomic conditions on adult health is examined the role of specific psychological attributes is worth further exploration, in addition to factors related to fetal development, early growth, and biological and behavioural mechanisms.

The study was conducted in close collaboration with the Public Health Services of the Dutch city of Eindhoven and the region of South East Brabant. We thank Michel Provoost and Ilse Oonk for carefully constructing the database and Carola Schrijvers and Mariel Droomers for their useful comments on previous drafts of the paper

Contributors: $\mathrm{HB}$ was the main author and carried out the analyses, interpreted data, and responded to referees' comments. HDvdeM formulated the hypothesis, helped with writing and responding to referees' comments, carried out preliminary analyses, and was partly responsible for data collection. JPM was principal investigator, formulated the hypothesis, helped with writing and responding to referees' comments, was responsible for data collection and is guarantor for the study.

Funding: Dutch Ministry of Public Health, Welfare, and Sports and the Dutch Prevention Fund.

Competing interests: None declared.

1 Davey Smith G, Hart C, Blane D, Gillis C, Hawthorne V. Lifetime socioeconomic position and mortality: prospective observational study. BMJ 1997;314:547-52

2 Davey Smith G, Hart C, Blane D, Hole D. Adverse socioeconomic conditions in childhood and cause specific adult mortality: prospective observational study. BMJ 1998;316:1631-5.

3 Kaplan GA, Salonen JT. Socioeconomic conditions in childhood and ischaemic heart disease during middle age. BMJ 1990;301:1121-3.

4 Lundberg $\mathrm{O}$. The impact of childhood living conditions on illness and mortality in adulthood. Soc Sci Med 1993;36:1047-52.

5 Rahkonen O, Lahelma E, Huuhka M. Past or present? Childhood living conditions and current socioeconomic status as determinants of adult health. Soc Sci Med 1997:44:327-36.

6 Forsdahl A. Are poor living conditions in childhood and adolescence an important risk factor for arteriosclerotic heart disease? BrJ Prev Med 1977;31:91-5

7 Barker DJP. Fetal and infant origins of adult disease. London: BMJ Books, 1992.

8 Forsdahl A. Living conditions in childhood and subsequent development of risk factors for arteriosclerotic heart disease. J Epidemiol Community Health 1978:32:34-7.

9 Blane D, Hart CL, Davey Smith G, Gillis CR, Hole DJ, Hawthorne VM. Association of cardiovascular disease risk factors with socioeconomic position during childhood and during adulthood. BMJ 1996;313:1434-8.

10 Lynch J, Kaplan G, Salonen J. Why do poor people behave poorly? Variation in adult health behaviours and psychosocial characteristics by stages of the socioeconomic lifecourse. Soc Sci Med 1997;44: 809-19.

11 Mheen H van de, Stronks K, Looman CWN, Mackenbach JP. Does childhood socioeconomic status influence adult health through behavioural factors? Int J Epidemiol 1998;27:431-7.

12 Wannamethee SG, Whincup PH, Shaper G, Walker M. Influence of father's social class on cardiovascular disease in middle-aged men. Lancet 1996;348:1259-63.

13 Lundberg O. Childhood conditions, sense of coherence, social class and adult ill health: exploring their theoretical and empirical relations. Soc Sci Med 1997;44:821-31.

14 SchwartzJE, Friedman HS, Tucker JS, Tomlinson-Keasey C, Wingard DL, Criqui MH. Sociodemographic and psychosocial factors in childhood as predictors of adult mortality. Am J Public Health 1995;85:1237-45.

15 McAdams DP. The person. An introduction to personality psychology. New York: Harcourt Brace Jovanovich, 1990.

16 Shaffer DR. Social and personality development. Pacific Grove, CA: Brooks/ Cole, 1994.

17 Scheier M, Bridges M. Person variables and health: personality predispositions and acute psychological states as shared determinants for disease. Psychosom Med 1995;57:255-68.

18 Ben-Shlomo Y, Davey Smith G. Deprivation in infancy or adult life: which is more important for mortality risk? Lancet 1991;337:530-4.

19 Mackenbach JP, Mheen van de H, Stronks K. A prospective cohort study investigating the explanation of socioeconomic inequalities in health in the Netherlands. Soc Sci Med 1994;38:299-308.
20 Erikson R, Goldthorpe J, Portocarero L. Intergenerational class mobility and the convergence thesis: England, France and Sweden. Br J Sociol 1983;34:303-42

21 Rotter J. Generalized expectancies for internal versus external control of reinforcement. Psychol Monogr 1966;80:1-28.

22 Andriessen JHTH. Interne of externe beheersing. Ned Tijdschrift Psycholog 1972;27:173-8.

23 Eysenck SBG, Eysenck HJ, Barrett PA. A revised version of the psychotism scale. Pers Ind Diff 1985;6:21-9.

24 Moody PM, Gray RM. Social class, social integration, and the use of preventive health services. In:Jaco EG, eds. Patients, physicians and illness. New York: Free Press, 1972.

25 Tax LCMM. Waarden, mentaliteit en beroep [PhD thesis]. Lisse: Swets and Zeitlinger, 1982:202 pp

26 Kohn ML. Class and conformity: a study in values. Chicago: Chicago University Press, 1977.

27 Schreurs P, Tellegen B, Vromans ISY, Willige G van de. De ontwikkeling van de Utrechtse Coping Lijst. Utrecht: Vakgroep Klinische Psychologie, Rijksuniversiteit Utrecht, 1983.

28 Appels A, Bosma H, Grabauskas V, Gostautas A, Sturmans F. Self-rated health and mortality in a Lithuanian and a Dutch population. Soc Sci Med 1996;42:681-9.

29 Idler EL, Benyamini Y. Self-rated health and mortality: a review of twenty-seven community studies. J Health Soc Behav 1997;38:21-37.

30 Ross CE, Mirowsky J. Explaining the social patterns of depression: control and problem solving-or support and talking? J Health Soc Behav 1989;30:206-19.

31 Wheaton B. The sociogenesis of psychological disorder: an attributional theory. J Health Soc Behav 1980;21:100-24.

32 Mirowsky J, Ross CE. Control or defence? Depression and the sense of control over good and bad outcomes. J Health Soc Behav 1990;31:71-86.

33 Smits CHM, Deeg DJH, Bosscher RJ. Well-being and control in older persons: the prediction of well-being from control measures. Int J Aging Hum Dev 1995;40:237-51.

34 Syme SL. Control and health: a personal perspective. In: Steptoe A, Appels A, eds. Stress, personal control and health. London: Wiley, 1989:3-18.

35 Anderson J. Empowering patients: issues and strategies. Soc Sci Med 1996;43:697-705.

36 Davey Smith G, Blane D, Bartley M. Explanations for socioeconomic differentials in mortality: evidence from Britain and elsewhere. Eur J Public Health 1994;4:131-44.

37 Mheen H van de, Stronks K, Schryvers CTM, Mackenbach JP. The influence of adult ill-health on occupational mobility out of and into the labour force in the Netherlands. A longitudinal study. Soc Sci Med (in press).

38 Ranchor AV, Sanderman R, Bouma J, Buunk BP, Heuvel WJ van de. An exploration of the relation between hostility and disease. J Behav Med 1997;20:223-40.

39 Watson D, Clark LA. Negative affectivity: the disposition to experience aversive emotional states. Psychol Bull 1984;96:465-90.

40 Kubzansky LD, Kawachi I, Spiro A III, Weiss ST, Vokonas PS, Sparrow D. Is worrying bad for your heart? A prospective study of worry and coronary heart disease in the normative aging study. Circulation 1997;95:81824.

41 Nyström Peck M, Lundberg O. Short stature as an effect of economic and social conditions. Soc Sci Med 1995;41:733-8.

42 Russek LG, Schwartz GE. Feelings of parental caring predict health status in midlife: a 35-year follow-up of the Harvard mastery of stress study. $J$ Behav Med 1997;20:1-13.

43 Friedman HS, Tucker JS, Tomlinson-Keasey C, Schwartz JE, Wingard DL, Criqui MH. Does childhood personality predict longevity? J Pers Soc Psychol 1993;65:176-85.

44 Meesters C, Muris P. The relationship between hostility and perceived parental rearing behaviour: a study of male myocardial infarction patients and healthy controls. Pers Ind Diff 1996;21:271-81.

(Accepted 20 October 1998)

\section{Endpiece \\ Gide's solution}

There is no psychological truth unless it be particular; but on the other hand there is no art unless it be general. The whole problem lies in just that-how to express the general by the particular-how to make the particular express the general. (André Gide)

Alice Heim, Intelligence and Personality (1970)

Submitted by Nicholas Steel, health services research fellow, University of East Anglia 